\title{
DESAIN WEB BAGI PEMULA MENGGUNAKAN FRAMEWORK BOOTSTRAP PADA SMK TARUNA BANGSA BEKASI
}

\author{
Mardi Yudhi Putra
${ }^{1}$, Nadya Safitri
Wahyudin Ratu Lolly \\ Rekayasa Perangkat Lunak, Fakultas Informatika, Universitas Bina Insani \\ $\underline{\text { mardi@binainsani.ac.id }}{ }^{1}, \underline{\text { nadyasafitri@binainsani.ac.id }}{ }^{2}, \underline{\text { nofiafilda@ binainsani.ac.id }}{ }^{3}$, \\ syafei456@gmail.com ${ }^{4}$, rayhan.wahyudin21@gmail.com ${ }^{4}$
}

\begin{abstract}
Abstrak
Penguasaan terhadap Teknologi Informasi dan Komunikasi perlu diajarkan pada semua tingkatan agar suatu proses dan kegiatan dapat dilakukan dengan lebih cepat, mudah dan efisien. Para siswa kelas XII SMK Taruna Bangsa dituntut untuk memiliki kompetensi yang dapat dikuasai sebelum lulus sekolah. Salah satunya kompetensi adalah dapat membuat website atau aplikasi berbasis web. Disamping itu, kepala program jurusan RPL SMK Taruna Bangsa menyampaikan perlu adanya pendalaman dan pengetahuan lebih dalam pembuatan website selain yang dibekali di sekolah seperti mendesain website front end. Oleh karena itu perlu dilakukan pelatihan mendesain website menggunakan framework Bootstrap. Pelaksanaan Pengabdian kepada Masyarakat (PkM) ini dijalankan sesuai dengan wujud implementasi MoU yang telah dilakukan antara SMK Taruna Bangsa dengan Universitas Bina Insani. Pelaksanaan kegiatan pada masa pandemi Covid-19 dilakukan secara online melalui media konferensi www.zoom.us dan www.youtube.com. Kegiatan ini diikuti oleh 78 peserta dengan hasil akhir memberikan hasil yang positif, ditunjukkan pada umpan balik peserta terhadap materi yaitu pada nilai 4 (Baik) sebesar 32,1\% dan nilai 5 (Sangat Baik) sebesar 60.7\%. Berdasarkan paparan tersebut kegiatan PkM ini telah memberikan kemampuan dan penguasaan terhadap siswa dalam mendesain website dan memiliki bekal dalam mengimplementasikan pada bidang Teknologi informasi yang pada akhirnya mendorong smart education kota Bekasi.
\end{abstract}

Kata kunci-bootstrap, pengabdian kepada masyarakat, website

\begin{abstract}
Mastery of Information and Communication Technology needs to be taught at all levels so that processes and activities can be carried out more quickly, easily and efficiently. Class XII students of SMK Taruna Bangsa are required to have competencies that can be mastered before graduating from school. One of the competencies is being able to create a website or web-based application. In addition, the head of the RPL department program at SMK Taruna Bangsa said that there is a need for more in-depth and knowledge in making websites other than those provided in schools such as designing front end websites. Therefore, training in designing websites using the Bootstrap framework is necessary. The implementation of Community Service $(P k M)$ is carried out in accordance with the implementation of the MoU that has been carried out
\end{abstract}


Mardi Yudhi Putra, Nadya Safitri, Nofia Filda Fauziah, Ahmad Safei, Rayhan Wahyudin

Ratu Lolly

Vol. 3 No 1, Februari 2021

ISSN 2657-0203

e-ISSN 2686-0244

between SMK Taruna Bangsa and Bina Insani University. The implementation of activities during the Covid-19 pandemic was carried out online through the 
ISSN 2657-0203

e-ISSN 2686-0244

media conference www.zoom.us and www.youtube.com. This activity was attended by 78 participants with the final result giving positive results, shown in the participants' feedback on the material, namely a value of 4 (Good) of $32.1 \%$ and a value of 5 (Very Good) of $60.7 \%$. Based on the explanation, this PkM activity has given students the ability and mastery in designing websites and has provisions in implementing it in the field of information technology which ultimately encourages smart education in the city of Bekasi.

Keywords-bootstrap, community service, website,

\section{PENDAHULUAN}

Permendikbud Nomor 6 Tahun 2019 Tentang Pedoman Organisasi Dan Tata Kerja Satuan Pendidikan Dasar Dan Menengah yang terdapat pada Ketentuan Umum Pasal 1 bahwa Sekolah Menengah Kejuruan yang selanjutnya disingkat SMK, adalah salah satu bentuk Satuan Pendidikan formal yang menyelenggarakan pendidikan kejuruan pada jenjang pendidikan menengah sebagai lanjutan dari SMP, MTs, atau bentuk lain yang sederajat atau lanjutan dari hasil belajar yang diakui sama atau setara SMP atau MTs [1].

SMK Taruna Bangsa Bekasi didirikan oleh Yayasan Pendidikan Nasional Taruna Bangsa pada tanggal 23 Agustus 2000 dan beralamat di Jalan Kali Abang Tengah, Perwira, Kec. Bekasi Utara, Kota Bekasi, Jawa Barat 17122. Dengan moto Mandiri Cerdas Berintegritas, SMK Taruna Bangsa memiliki beberapa program keahlian yaitu Teknik Kendaraan Ringan, Teknik Elektronika, Teknik Listrik dan Teknik Komputer dan Informatika

(RPL). Program Keahlian Teknik Komputer dan Informatika memiliki beberapa kompetensi yang diharapkan dapat dikuasai oleh siswanya di masing-masing tingkatan. Berikut merupakan kompetensi kelas Xii Komputer \& Informatika adalah dapat membuat website atau aplikasi berbasis web tingkat lanjut menggunakan (CI atau Laravel), dapat membuat aplikasi berbasis desktop dengan menggunakan VB. Net tingkat lanjut dan dapat membuat aplikasi mobile (Android/Mobile Aplication) [2].

Perkembangan dunia Teknologi Informasi dan Komunikasi berkembang dengan pesat dan pada abad 21 dan menghadapi Revolusi Industri 4.0 ini pula sudah menjadi kebutuhan primer bagi banyak kalangan. Dengan menggunakan Teknologi Informasi dan Komunikasi, suatu proses dan kegiatan dapat dilakukan dengan lebih cepat, mudah dan efisien. Oleh karena itu penguasaan terhadap perangkat Teknologi Informasi dan Komunikasi perlu diajarkan pada semua tingkatan. Teknologi informasi adalah ilmu yang mempelajari penggunaan teknologi sebagai media dalam pengelolaan informasi [3].

Kemampuan penguasaan teknologi dan informasi pada siswa-siswi SMK Taruna Bangsa Bekasi khususnya dalam penguasaan membuat website sangat diperlukan. Untuk 


\section{Mardi Yudhi Putra, Nadya Safitri, Nofia Filda Fauziah, Ahmad Safei, Rayhan Wahyudin}

Ratu Lolly

Vol. 3 No 1, Februari 2021

ISSN 2657-0203

e-ISSN 2686-0244

mendukung tercapainya kompetensi yang ada pada kelas XII Komputer dan Informatika maka perlu dilakukan pelatihan mulai dari membuat dan mendesain website menggunakan framework Bootstrap bagi siswa-siswi SMK Taruna Bangsa yang ada di kota Bekasi. Disamping itu, permasalahan yang diidentifikasi berdasarkan diskusi dengan kepala program rekayasa perangkat lunak SMK Taruna Bangsa adalah para siswa masih belum memahami bagaimana mendesain website front end dan bagaimana memanfaatkan framework CSS dalam mendesain website sehingga fokus ke tampilan mobile. Oleh karena itu dapat disimpulkan perlu adanya pendalaman dan pengetahuan lebih dalam mengenai pengembangan website dengan menggunakan Framework Bootstrap.

Pada dasarnya website merupakan aplikasi yang berisikan dokumen-dokumen multimedia baik teks, gambar, suara, animasi, video yang didalamnya menggunakan protokol HTTP (Hypertext Transfer Protocol) dan untuk mengaksesnya menggunakan browser [4].

HTML (Hypertext Markup Languange) merupakan salah satu format yang digunakan dalam pembuatan dokumen dan aplikasi yang berjalan di halaman web. Oleh karena itu agar dapat membuat program aplikasi diatas halaman web, anda terlebih dahulu harus mengenal dan menguasai HTML [5].

HTML dan CSS merupakan kode paling dasar yang perlu dikuasai oleh siapa pun yang ingin belajar desain website dari nol. HTML merupakan singkatan dari Hypertext Markup Language. Disebut hypertext karena didalam script HTML bisa membuat agar teks menjadi link yang dapat berpindah dari satu halaman ke halaman lainnya dengan mengklik teks tersebut. Teks yang berlink inilah yang dinamakan hypertext karena hakikat sebuah website adalah dokumen yang mengandung banyak link untuk menghubungkan satu dokumen dengan dokumen-dokumen lainnya [6].

CSS digunakan untuk mengubah tampilan yang dihasilkan oleh tag HTML karena bekerja dengan kode yang berbda, maka CSS membutuhkan suatu mekanisme untuk menempelkan kode-kode CSS tersebut dengan tag HTML yang baik dari sinilah muncul konsep selektor dalam CSS. Selektor digunakan untuk mencari bagian dalam halaman website yang ingin diubah tampilannya [7].

Bootstrap merupakan sebuah framework CSS, yang menyediakan kumpulan komponen-komponen antarmuka dasar pada web yang telah dirancang semdemikian rupa untuk digunakan bersama-sama. Selain komponen antarmuka, bootstrap juga enyediakan sarana untuk membangun layout halaman dengan mudah dan rapi, serta modifikasi pada tampilan dasar HTML untuk membuat seluruh halaman web yang dikembangkan senada dengan komponen-komponen lainnya [8]. 
ISSN 2657-0203

e-ISSN 2686-0244

Responsive web design merupakan sebuah desain website yang dapat menyesuaikan tiap ukuran pada tiap devices. Penerapan responsive design ini di kombinasikan pada flexible grids, javascript, CSS media queries dan HTML. Manfaat dari responsive web design yaitu sebuah website yang dapat beradaptasi pada tata letak ukuran devices dengan ukuran font, gambar dan komponen lainnya tanpa harus melakukan horizontal scrolling [9].

Dalam mendesain template aplikasi berbasis web, programmer web menggunakan sintak-sintak CSS untuk membuat tampilan menjadi lebih menarik. Dalam perkembangannya banyak tools atau framework CSS yang dapat dimanfaatkan untuk mempercepat pengerjaan desain template web, diantaranya Gumby, Foundation, Less Framework, Blueprint CSS dan Twitter Bootstrap. Dari beberapa framework CSS tersebut, Twitter Bootstrap hadir dengan tutorial dan dokumentasi yang berlimpah serta memiliki fitur responsive [10]. Penerapan bootstrap digunakan khususnya untuk membuat header halaman web, menu item menarik dan responsive [11].

Pengabdian kepada Masyarakat atau biasa disebut dengan PkM dilakukan oleh sivitas akademika memanfaatkan IPTEK untuk kemajuan dan kesejahteraan masyarakat [12]. Sesuai dengan pernyataan permendikbud maka tujuan dari Kegiatan PkM Desain Website bagi Pemula menggunakan Bootstrap untuk memberikan kemampuan dalam menguasai bahasan desain web dengan rician penguasaan yaitu 1) Mampu membuat website frontend. 2) Mampu menggunakan framework Bootstrap

3) Memahami pembuatan website responsive. 4) para siswa memiliki bekal dalam mengimplementasikan pada bidang Teknologi informasi. 5) Wujud implementasi kerjasama yang telah dilakukan oleh Univeristas Bina Insani dengan SMK Taruna Bangsa yang pada akhirnya dapat mendorong Smart education kota Bekasi. Disamping itu adapun manfaat yang diperoleh bagi perguruan tinggi yakni melaksanakan kewajiban salah satu Tridharma perguruan tinggi melalui kegiatan pengabdian kepada masyarakat (PkM), meningkatkan kemampuan dosen melalui proses sharing keahlian dengan peserta sesuai dengan kompetensi yang dimiliki. Bagi peserta memahami konsep mendesain website menggunakan bootstrap.

\section{METODE}

Berdasarkan penjelasan pada pendahuluan dan permasalahan yang dihadapi mengenai kemampuan dalam mendesain website solusi yang diusulkan oleh Program Studi Rekayasa Perangkat Lunak Fakultas Informatika Universitas Bina Insani adalah mengadakan Pelatihan Online dengan tema "Desain Website bagi Pemula menggunakan Bootstrap" untuk Siswa kelas XII Jurusan Rekayasa Perangkat Lunak SMK Taruna Bangsa Bekasi dengan fasilitas Zoom 
Vol. 3 No 1, Februari 2021

ISSN 2657-0203

e-ISSN 2686-0244

secara online yang dilaksanakan selama 1 (satu) hari. Adapun metode yang digunakan dalam pelaksanaan Pengabdian kepada Masyarakat dijelaskan melalui gambar 1.

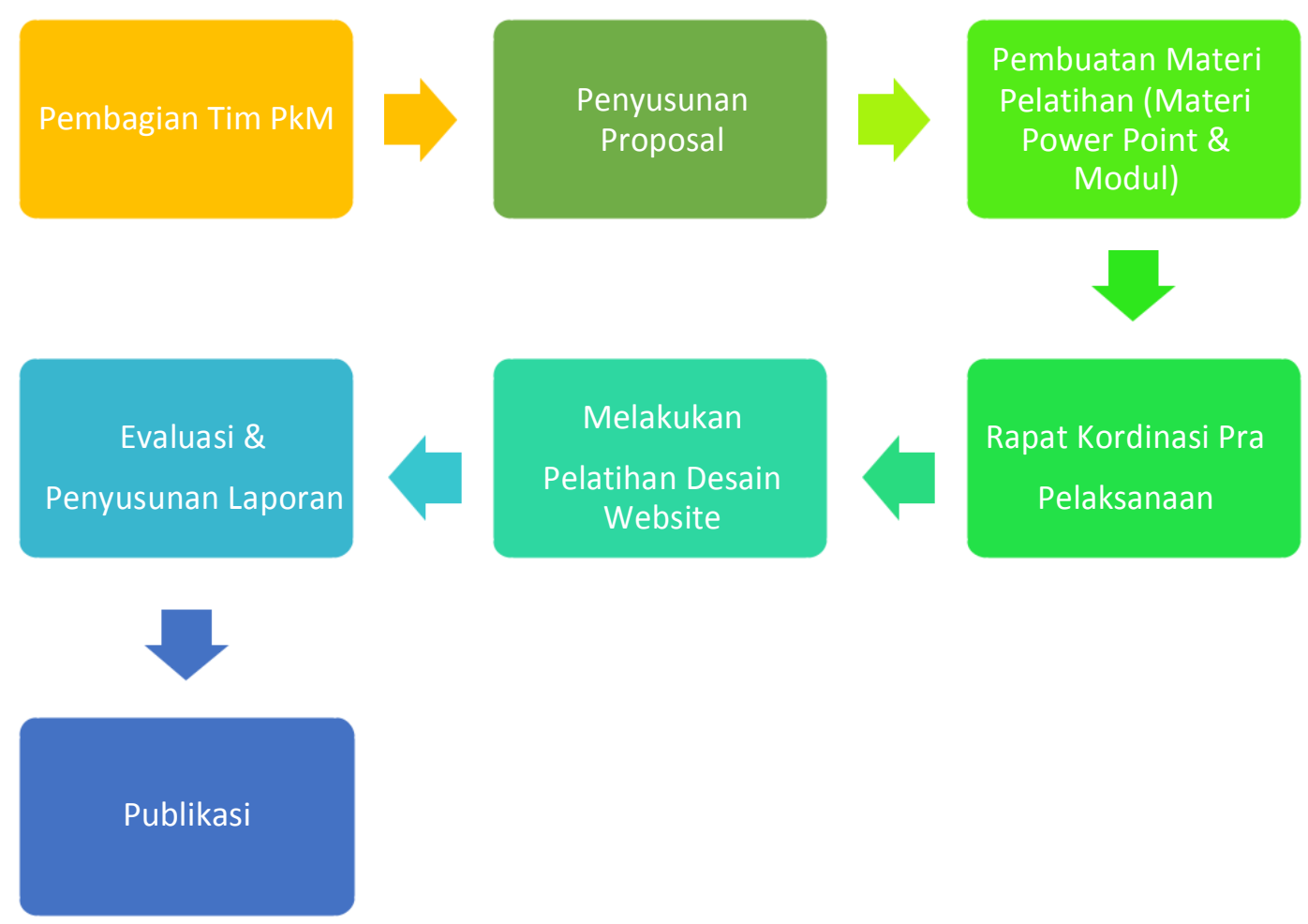

\section{Gambar 1. Langkah-langkah PkM Desain Web}

Adapun jumlah peserta dari SMK Taruna Bangsa Bekasi sejumlah 78 (tujuh puluh delapan) peserta. Mengingat masih dalam masa pandemi COVID-19, kegiatan PkM ini dilaksanakan pada tanggal 29 Januari 2021 secara online. Kegiatan PkM Online tersampaikan melalui media-media seperti media online zoom meeting, media online youtube, media berita. Kegiatan pelatihan secara online melalui aplikasi Zoom meeting sebagaimana ditunjukkan seperti pada gambar 2 berikut.

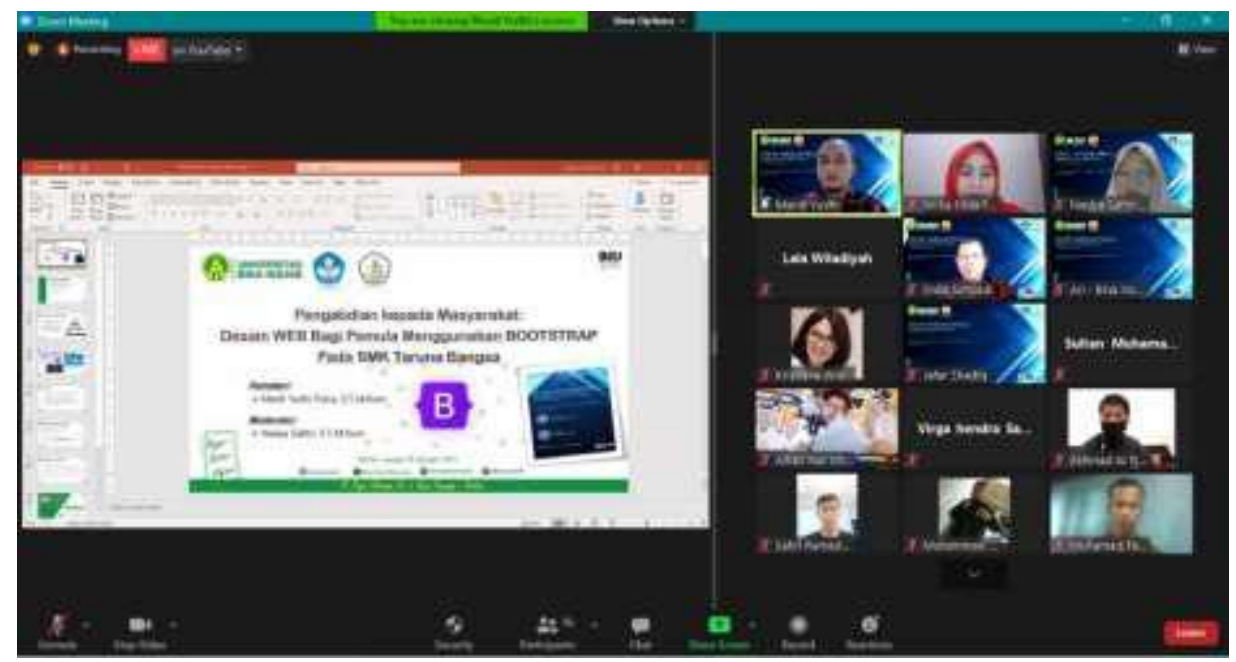


Gambar 2. Kegiatan PkM Desain Website Bagi Pemula melalui aplikasi Zoom

Untuk dapat mengikuti kegiatan PkM Online, peserta dapat mengakses alamat link https://zoom.us/j/94864730003?pwd=VzNGUVVSSmtONj12RVhMN25TSHlaZz09 dengan passcode: PkM-RPL20 sebagaimana melalui Group WhatsApps disampaikan oleh pihak SMK Taruna Bangsa kota Bekasi sebagai fasilitator kegiatan. Kegiatan PkM juga disiarkan secara Live melalui chanel resmi youtube Bina Insani University melalui link berikut https://youtu.be/2X6v2_Xgzv0, sebagaimana terlihat pada gambar 3.

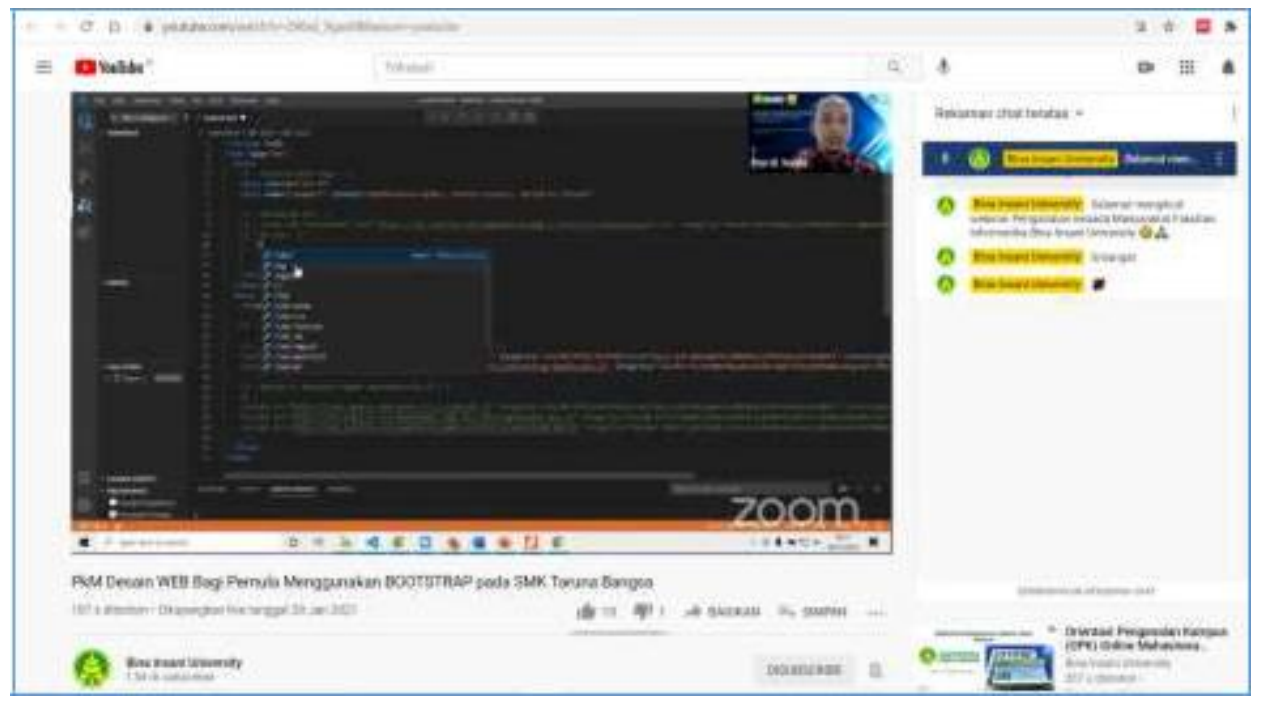

Gambar 3. Kegiatan PkM melalui Youtube

Kegiatan PkM desain website juga disampaikan melalui media berita online yang dapat diakses melalui link http://www.ikabari.com/web/2021/02/04/pkm-desain-web-bagi-pemuladengan-menggunakan-bootstrap-pada-smk-taruna-bangsa-bekasi/.

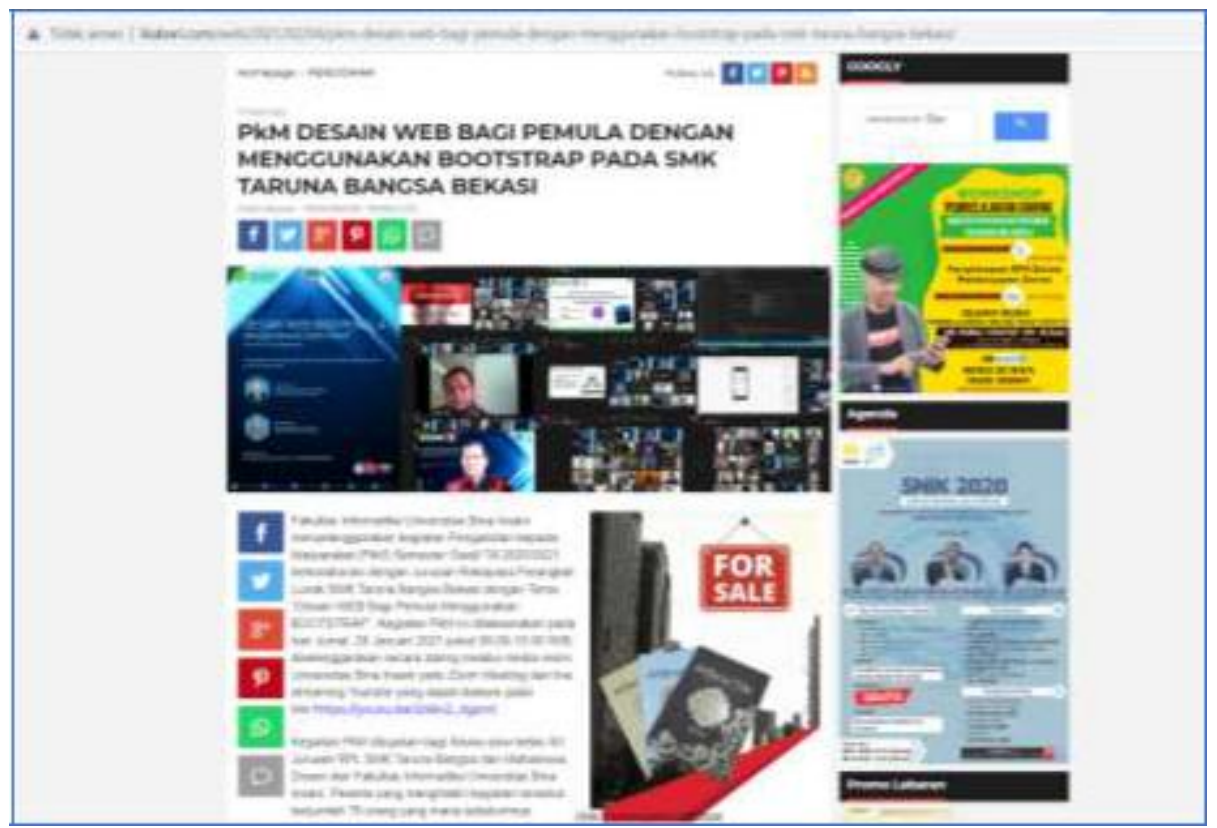




\section{Gambar 4. Kegiatan PkM pada media massa online}

Disamping penyampaian media yang digunakan untuk mendukung pelaksanaan kegiatan PkM desain web 2 hari sebelum kegiatan berlangsung peserta dibagikan modul dan materi desain web agar dapat dipelajari terlebih dahulu dan diwajibkan untuk menginstal tools pendukung kegiatan seperti code editor visual studio code/ sublime text serta web browser seperti google chrome maupun mozila firefox.

\section{HASIL DAN PEMBAHASAN}

Hasil pelaksanaan kegiatan pengabdian kepada masyarakat setelah mengikuti kegiatan desain website bagi pemula diharapkan seluruh peserta siswa-siswi SMK Taruna Bangsa Kota Bekasi dapat mengaplikasikan konsep Desain Website frontend dan penggunaan framework Bootstrap. Kegiatan ini juga sebagai target capaian dari implementasi kerjasama Universitas Bina Insani dengan SMK Taruna Bangsa Kota Bekasi dan untuk mendukung isian borang kriteria 9 APT dan APS. Wujud dari target pencapaian kegiatan PkM dapat dilihat melalui jumlah peserta pendaftar dan respon feedback dari peserta setelah mengikuti kegiatan PkM.

Berdasarkan form pendaftaran peserta kegiatan PkM melalui link Google Form yang disediakan pada link http://bit.ly/absensipkmbootstrap kegiatan PkM ini diikuti oleh peserta sebagai siswa sebanyak (76.9\%), Guru sebanyak (3.8\%) dan lainnya sebanyak (19.2\%). Disamping itu, juga disampaikan instansi yang mengikuti kegiatan ini dari SMK Taruna Bangsa $(73.1 \%)$ dan dari universitas bina insani sebanyak (26.9\%).

\section{Capaian Hasil Pemahaman Peserta Terhadap Materi Pelatihan}

Kegiatan Pengabdian kepada Masyarakat dengan tema "Desain Website bagi Pemula menggunakan Bootstrap” yang diadakan sesuai dengan kebutuhan dari SMK Taruna Bangsa Bekasi yaitu dalam mendukung tercapainya kompetensi yang ada pada kelas XII Komputer dan Informatika jurusan rekayasa perangkat lunak dengan memberikan bekal pendalaman dan pengetahuan kepada para siswa siswi SMK Taruna Bangsa Bekasi melalui kegiatan PkM desain website bagi pemula menggunakan Bootstrap semoga dapat meningkatkan kemampuan penguasaan teknologi dan informasi guna diterapkan didunia kerja.

Setelah mengikuti kegiatan PkM secara online diakhir kagiatan peserta memberikan umpan balik (feedback) terhadap kegiatan ini melalui Google Form pada link http://bit.ly/angketpkmbootstrap diperoleh sebanyak 56 (lima puluh enam) peserta memberikan umpat balik terhadap materi pelatihan, respon peserta terhadap materi, hubungan materi sesuai kebutuhan, keterkaitan materi dengan aplikasi yang dapat diserap, 
keterkaitan materi dengan kebutuhan, pemateri dan teknik penyajian, waktu yang dipergunakan dalam pemberian materi, kejelasan materi, minat peserta terhadap kegiatan, tingkat kepuasan kegiatan secara keseluruhan, saran untuk kegiatan selanjutnya dan saran untuk panitia kegiatan.

Tabel 1 Capaian hasil kegiatan PkM

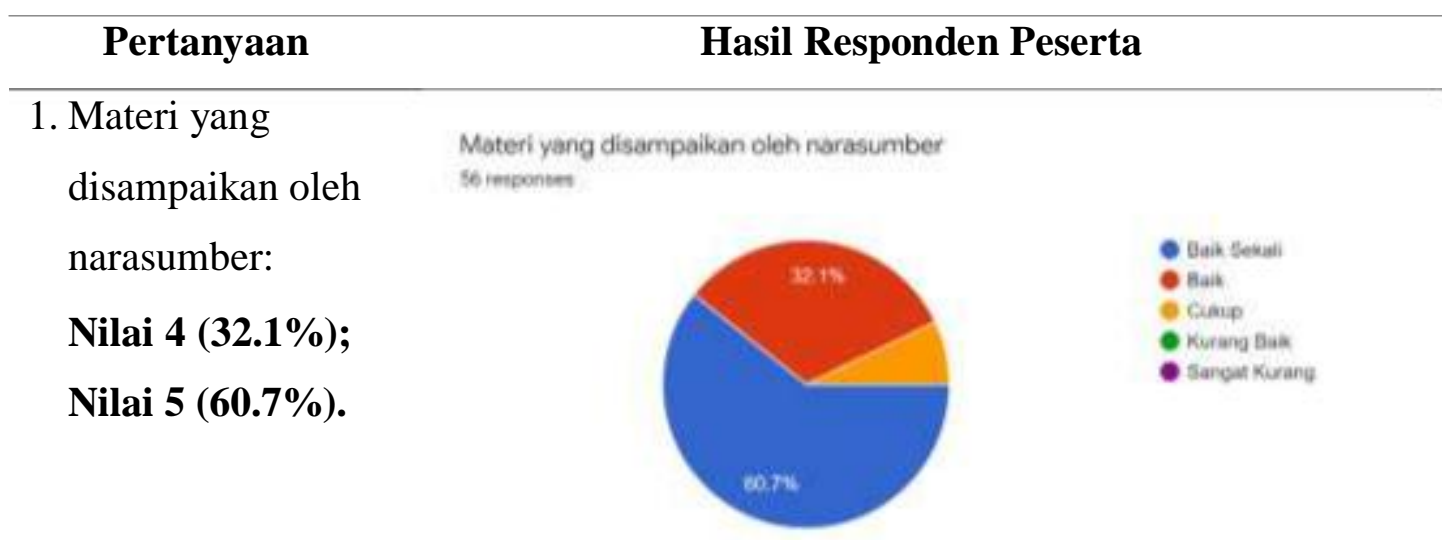

2. Respon peserta pelatihan terhadap materi yang disampaikan Nilai 4 (46.4\%); Nilai $5(39.3 \%)$. Respon peserta pelatihan terhadap materi yang disampaikan sh rewonses

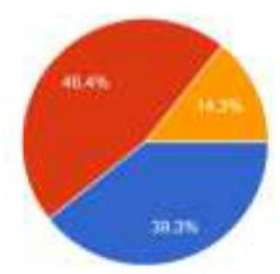

3. Hubungan materi yang disajikan dengan kebutuhan peserta pelatihan

Nilai 4 (44.6\%);

Nilai 5 (48.2\%).
Hubungan materi yang disajikan dengan kebutuhan peserta pelatihan 56 responses

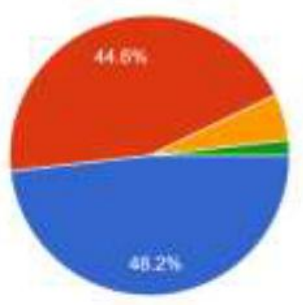

- Bak Sekal

Bak

Cukup

- Kurang Bak

- Sangat Kurang 
4. Keterkaitan antara

Keterkaitan antara materi dengan aplikasi yang dapat diserap peserta pelatihan

materi dengan

aplikasi yang

dapat diserap

peserta pelatihan

Nilai 4 (50\%);

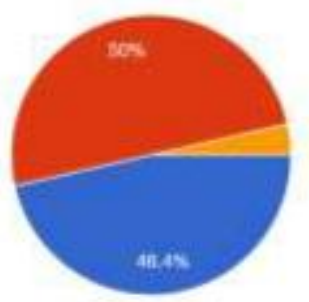

CAakr Beaul

Bak

e cinut

- Kurang gaa

- sangar kurang

Nilai 5 (46.4\%).

5. Keterkaitan

materi dengan

Keterkaitan materi dengan kebutuhan

So responses

kebutuhan

Nilai 4 (35.7\%);

Nilai 5 (55.4\%).

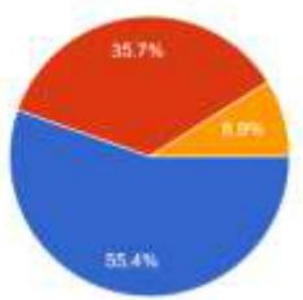

6. Pemateri dan

teknik penyajian

Pemateri dan teknik penyajian

56 responses

Nilai 4 (32.1\%);

Nilai $5(50.0 \%)$.

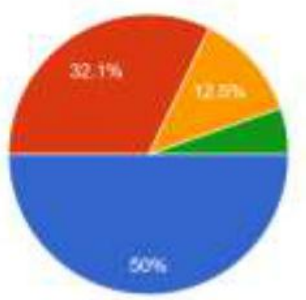

7. Waktu yang

dipergunakan

Waktu yang dipergunakan dalam pemberian materi

dalam pemberian

materi

Nilai 4 (26.8\%);

Nilai 5 (32.1\%).

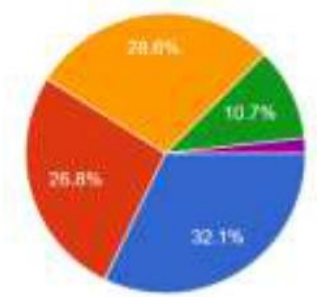


8. Kejelasan materi

$$
\begin{aligned}
& \text { Kejelasan materi } \\
& \text { so imponses }
\end{aligned}
$$

Nilai 4 (42.9\%);

Nilai $5(32.1 \%)$.
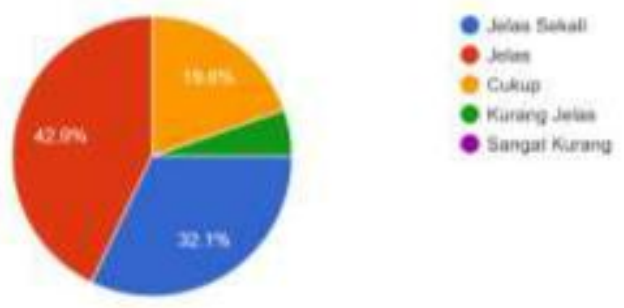

Minat peserta pelatihan terhadap kegiatan

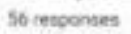

pelatihan terhadap

kegiatan

Nilai $4(39.3 \%)$;

Nilai 5 (46.4\%).
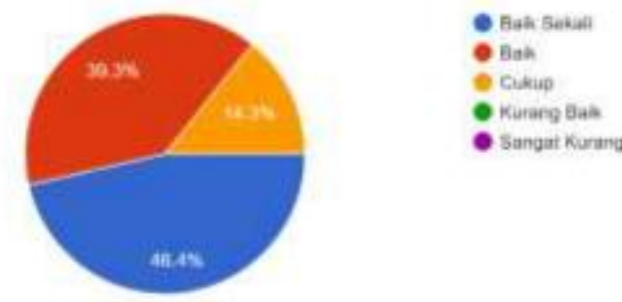

10. Tingkat

kepuasan

terhadap kegiatan

secara

keseluruhan.

Nilai 4 (37.5 \%);

Tingkat kepuasan terhadap kegiatan secara keseluruhan

50 rescontes

Nilai $5(44.6 \%)$.

11. Saran untuk• Melanjutkan materi mengenai penggunaan boostrap ini

materi pelatihan

yang akan datang
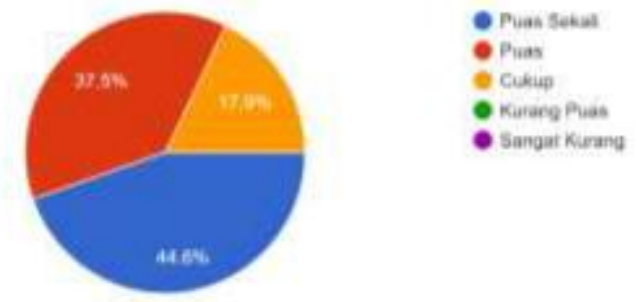

- Mencoba framework yang lain selain bootstrap

- cukup membantu dalam pelajar web

- materi selanjutnya tentang laravel

- Tidak ada saran sudah cukup mungkin doanya di masa yang akan mendatang sudah tidak ada pandemi agar bisa bertatap muka

- Semoga ada lagi pelatihan seperti ini 
Vol. 3 No 1, Februari 2021

ISSN 2657-0203

e-ISSN 2686-0244

- Penyampaian materi nya sudah bagus, gampang buat ditangkep dan pastinya ilmu nya sangat bermafaat buat Design web

12. Saran untuk• Untuk lebih sering mengadakan pelatihan seperti ini. panitia kegiatan

- Semoga bisa terus menyampaikan materi materi yang bermanfaat seperti ini

- Lebih sering dilakukan web binar

- sangat baik sekali, dan terima kasih atas pelatihan webinar ini

- Terima kasih banyak atas pelatihannya. Semoga kedepannya ada pelatihan seperti ini lagi di akan datang

- menurut saya kepanitianya sudah baik semoga kedepan nya juga lebih baik juga terimakasih atas ilmunya sangat bermanfaat.

- Terima kasih banyak untuk panitia kegiatan Kerja yang Bagus semoga bisa bertemu di lain waktu

Disamping itu, capaian hasil kegiatan PkM juga dapat terlihat dari project desain website yang dibuat dan dikirimkan peserta SMK Taruna Bangsa ke email narasumber dengan waktu 1 minggu setelah pelaksanaan kegiatan PkM selesai dilakukan. Berikut ini beberapa hasil project yang dibuat peserta ditunjukkan pada gambar 4 . 
Vol. 3 No 1, Februari 2021

ISSN 2657-0203

e-ISSN 2686-0244
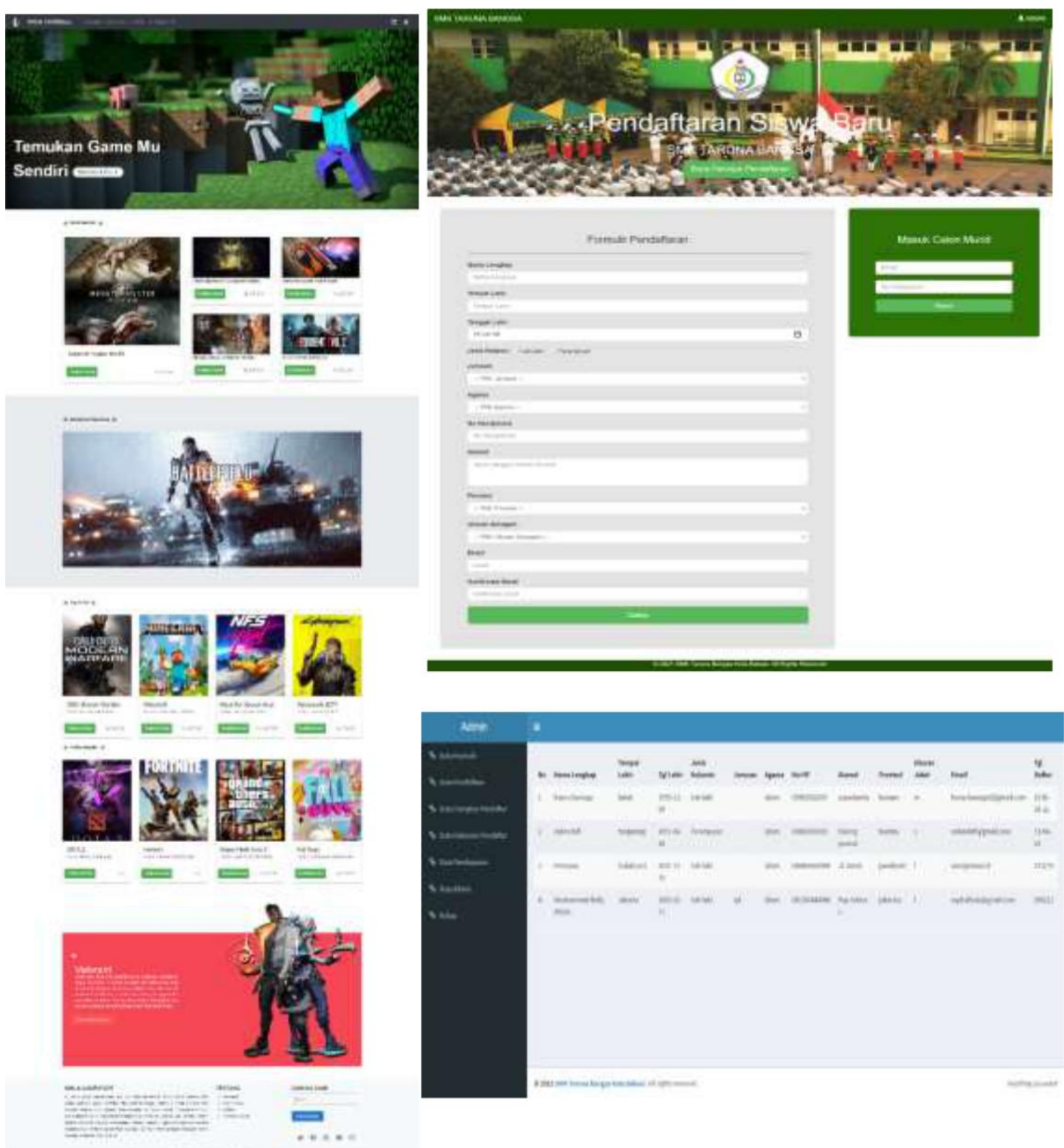

Gambar 5. Hasil project desain website peserta kegiatan PkM 


\section{Capaian Hasil Standar Akreditasi Program Studi (APS) 9 Kriteria dan MoU}

Terlaksananya kegiatan PkM Desain Website bagi pemula memberikan peran penting sebagai salah satu pemenuhan Tridarma Perguruan Tinggi semester Ganjil 2020/2021 dan merupakan salah satu komponen dalam butir penilaian laporan kinerja program studi butir PkM 3b3 APS yaitu Pengabdian kepada Masyarakat (PkM) yang dilaksanakan oleh Dosen Tetap Program Studi (DTPS) yang relevan dengan bidang program studi Rekayasa Perangkat Lunak.

\section{KESIMPULAN DAN SARAN}

Kegiatan pengabdian kepada masyarakat Desain Website bagi pemula menggunakan Bootstrap pada SMK Taruna Bangsa Bekasi dilaksanakan secara online memberikan kemampuan: 1) Mampu membuat website frontend hal ini terlihat dari umpan balik peserta pelatihan terhadap materi kegiatan secara keseluruhan memberikan respon yang positif yaitu pada Nilai 4 (Baik) 32,1\% dan Nilai 5 (Sangat Baik) 60.7\%.2) Mampu menggunakan framework Bootstrap pada studi kasus hal ini terlihat dari umpan balik peserta terhadap sasaran pelatihan secara keseluruhan memberikan respon yang positif yaitu pada Nilai 4 (Baik) 37.5\% dan Nilai 5 (Sangat Baik) 44.6\%. 3) memiliki bekal dalam mengimplementasikan pada bidang Teknologi informasi ini dapat terlihat pada bagian pembahasan capaian hasil kegiatan, peserta dapat membuat project desain web menggunakan Framework. 5) Wujud implementasi kerjasama yang telah dilakukan oleh Univeristas Bina Insani dengan SMK Taruna Bangsa Bekasi yang pada akhirnya dapat mendorong Smart education kota Bekasi hal ini juga dapat terlihat pada peserta dengan harapan adanya pelatihan lanjutan dengan teknologi Framework lainnya sesuai dengan keilmuan yang ada pada Universitas Bina Insani.

\section{DAFTAR PUSTAKA}

[1] Permendikbud, Peraturan Menteri Pendidikan Dan Kebudayaan Republik Indonesia Nomor 6 Tahun 2019 Tentang Pedoman Organisasi Dan Tata Kerja Satuan Pendidikan Dasar Dan Menengah. Jakarta: Republik Indonesia, 2019.

[2] Admin, "Sejarah," [Online]. 2014, Available: https://www.smktarunabangsa.sch.id/isi/halaman/detail/sejarah.

[3] M. Sobri, Emigawaty, and N. R. Damayanti, Pengantar Teknologi Informasi, Konsep dan Teori. Yogyakarta: Andi, 2017.

[4] F. Effendy and B. Nuqoba, "Penerapan Framework Bootsrap Dalam Pembangunan Sistem Informasi Pengangkatan Dan Penjadwalan Pegawai (Studi Kasus:Rumah Sakit Bersalin Buah Delima Sidoarjo) | Effendy | Informatika Mulawarman : Jurnal Ilmiah Ilmu Komputer,” 2016, Accessed: Feb. 08, 2021. [Online]. Available: http://ejournals.unmul.ac.id/index.php/JIM/article/view/197/pdf. 
Vol. 3 No 1, Februari 2021

ISSN 2657-0203

e-ISSN 2686-0244

[5] S. Zakir and Amrizal, "Kupas Tuntas Pemograman Berbasis Web, HTML, PHP, Java + MySQL," F, no. January, p. 35, 2019.

[6] Jubilee Enterprise, Pengenalan HTML dan CSS. Jakarta: PT. Elek media komputindo, 2016.

[7] Jubilee Enterprise, 5 Pemrograman Dasar Desain Website. Jakarta: PT Elex Media Komputindo, 2019.

[8] J. S. K. Songko and T. Wahyono, "Perancangan Aplikasi Pembelajaran Berbasis Responsive Web Desain Studi Kasus pada Universitas Tadulako Artikel Ilmiah Program Studi Teknik Informatika Fakultas Teknologi Informasi Universitas Kristen SatyaWacana Desember 2014 Perancangan Aplikasi Pembelaj,” no. 672009153, 2014.

[9] C. Novianty, "Review Konsep Responsive Design Dengan Framework Materialize Pada Website," InfoTekJar (Jurnal Nas. Inform. dan Teknol. Jaringan), vol. 2, no. 1, pp. 41-44, 2017, doi: 10.30743/infotekjar.v2i1.140.

[10] M. A. Rosid and R. B. Jakaria, "Implementasi Framework Twitter Bootstrap Dalam Perancangan Aplikasi Penerimaan Mahasiswa Baru Berbasis Web," Kinetik, vol. 1, no. 3, p. 129, 2016, doi: 10.22219/kinetik.v1i3.121.

[11] Wijayanto, "Penerapan Teknologi Responsive Web Design menggunakan Library Bootstrap Untuk Pembuatan Aplikasi E-journal pada Yayasan Bina Darma Salatiga," no. 672012055, 2016.

[12] Permendikbud, Peraturan Menteri Pendidikan dan Kebudayaan Republik Indonesia Nomor 49 Tahun 2014 Tentang Standar Nasional Pendidikan Tinggi. Jakarta: Republik Indonesia, 2014. 